\title{
A atenção psicossocial em saúde mental: contribuição teórica para o trabalho terapêutico em rede social
}

\author{
Nilson Gomes Vieira Filho \\ Sheva Maia da Nóbrega \\ Universidade Federal de Pernambuco
}

\begin{abstract}
Resumo
O objetivo principal deste artigo é dar uma contribuição teórica psicossocial ao trabalho terapêutico em rede social, recomendado para os serviços comunitários, no contexto da reforma psiquiátrica brasileira. Considerase que a porta de entrada desses serviços no SUS (Sistema Unificado de Saúde) seria o CAPS (Centro de Atenção Psicossocial) em saúde mental e o PSF (Programa de Saúde da Família) em saúde geral. O trabalho terapêutico em rede social, nessa primeira micro-organização territorial, funcionaria no interior de uma rede articulada e solidária de unidades sanitárias e inserido em políticas públicas de não abandono ao usuário. Estuda-se principalmente o processo de desconstrução das redes de instituições totais em saúde mental, no circuito hospitalocêntrico, e a construção de um novo sistema de saúde mental que funcione numa dinâmica institucional autopoiética. Essa situação facilitaria então as mediações dialógicas nas relações terapêuticas e entre os diversos atendimentos, com conexões intra e inter institucionais, como também contribuiria para a inserção social do usuário. Em conseqüência, a psicoterapia praticada no CAPS incluiria tanto a possibilidade de variações no enquadre, quanto às intervenções na rede pessoal significativa do usuário, quando necessárias. Conclui-se que estaria havendo, em muitos casos, decalagem entre a teorização proposta e a prática instituída no SUS. Recomenda-se que nas práticas técnico-profissionais e nas políticas públicas sejam tomadas medidas concretas que possam superar esta situação no sentido de melhor qualificar os atendimentos em saúde mental.

Palavras-chaves: desconstrução institucional; atenção psicossocial; rede social
\end{abstract}

\begin{abstract}
Psychosocial mental health attention: theoretical contribution for a network therapeutic approach. The most important objective of this article is to contribute for a psychosocial approach in therapeutic network, recommended for community services, in the context of the psychiatric Brazilian reform. The entrance door of those services in the SUS (Unified Health System) would be a Community Mental Health Center (CAPS) for this specialty and a PSF (Health Family Program) for a generalist health approach. The therapeutic network in the first micro-organization would function into an institutional system articulated and in solidarity with health organizations and also inserted in public policies programs that intend not to abandon the patient. The focus in this study is a process of deconstruction of the total institutions in mental health that forms a traditional circuit centered in the psychiatric hospital and a construction of a new mental health system that could function according to an autopoietic institutional dynamics. This situation could facilitated dialogical mediations in therapeutic relations and between the interventions connected with other institutions and could contribute for the social insertion of the user. Consequently, the psychotherapy practiced at the CAPS could include the possibilities of setting variations and network interventions in the significant social network of the patient, if necessary. It is concluded that there would be, in many cases, a dichotomy between this theorization and the practice in mental health in the SUS. It is recommended that the necessary steps should be taken in professional practices and public policies programs in order to overcome this dichotomy and qualify the mental health interventions.
\end{abstract}

Keywords: institutional deconstruction; psychosocial attention; social network

$\mathrm{O}$ objetivo principal deste artigo é dar uma contribuição teórica psicossocial à prática terapêutica em rede social, indicada como pertinente para os serviços comunitários, no contexto da reforma psiquiátrica. Trata-se de uma abordagem psicossocial sobre práticas institucionais
(Vieira Filho, 1997; Vieira Filho \& Morais, 2003), desenvolvida no grupo de trabalho da ANPEPP (Associação Nacional de Pesquisa e Pós-graduação em Psicologia), intitulado "Práticas psicológicas em instituições", há mais de cinco anos. O autor principal é pesquisador e terapeuta, implicado em tra- 
balho terapêutico dessa natureza e com longo tempo de experiência de atendimentos no âmbito do sistema público. A partir dessa implicação clínica e de outras fontes de informações (bibliográficas, observações semestrais de alunos nos Centros de Atenção Psicossocial-CAPS, entre outras), este artigo foi elaborado com a colaboração do segundo autor.

Tenta-se construir elementos conceituais significativos, multireferenciais, originados de múltiplos registros, que articulam a micro-situação interativa da atenção psicossocial em saúde mental com o processo de desconstrução da rede de instituições totais ${ }^{1}$, nessa especialidade. Não se isola uns ou outros fatores que interferem no contexto; pelo contrário, preserva-se "a complexidade da situação psicossocial para analisá-la através de seus componentes e combinações" (Barus-Michel, Giust-Desprairies, \& Ridel, 1996, p. 287). O que quer dizer, essencialmente, situação processual de relações humanas, inseridas numa rede social complexa, transversais às instituições e à(s) cultura(s) vivenciada(s) dos sujeitos implicados.

Nesse sentido, focalizam-se as redes de relações profissionais no CAPS, ou serviço equivalente, de caráter intra e interinstitucional, bem como as redes significativas do usuário, numa perspectiva de intervenção clínica. Essas redes são entendidas numa dinâmica de colaboração solidária entre profissionais, usuários e comunidade, no contexto de políticas públicas de não abandono ao usuário e de desconstrução do circuito hospitalocêntrico em saúde mental.

\section{O contexto da reforma psiquiátrica brasileira: a Portaria 336/02 do Ministério da Saúde}

A Lei federal $n^{\circ} 10.216$, de 06/04/2001, da reforma psiquiátrica brasileira, dispõe sobre o redirecionamento do modelo assistencial em saúde mental e os direitos das pessoas ditas portadoras de transtornos mentais. Discorre que esses cidadãos devem ser tratados, preferencialmente, em serviços comunitários "com humanidade e respeito e no interesse exclusivo de beneficiar a saúde, visando alcançar sua inserção na família, no trabalho e na comunidade" (Art. $2^{\underline{0}}$, II). Segundo a Portaria n⿳⺈ 336/2002 do Ministério da Saúde, os CAPS (Centros de Atenção Psicossocial - I, II, III) seriam os mais representativos desses serviços, que têm como prioridade "o atendimento de pacientes com transtornos mentais severos e persistentes em sua área territorial, em regime de tratamento intensivo, semi-intensivo e não intensivo" (Art. $\left.1^{\underline{o}}, 1\right)$.

Esses centros apresentam um nível de complexidade de atenção que inclui também a internação (CAPS-III) podendo, assim, substituir o hospital psiquiátrico. Previsto para ser porta de entrada em saúde mental no Sistema Unificado de Saúde (SUS), esta instituição assume assim sua parte de responsabilidade na administração e centralidade dos atendimentos no território. Deve também capacitar e supervisionar as equipes de atenção básica e outros serviços de saúde mental, bem como contribuir na elaboração de programas nessa área. Sendo assim, essa Portaria traz novas regras instituídas que possibilitam uma reforma psiquiátrica mais efetiva, que possa superar a rede de instituições totais do circuito hospitalocêntrico.
O processo de desconstrução da rede de instituiçães totais e das representações sociais excludentes

Goffman (1980) conceitua a instituição total como uma organização que atua com uma estrutura de poder englobante (ou total) e funciona com restrições às trocas sociais. Possui um sistema rigoroso de normas formais explícitas e um corpo de pessoas aderentes que permite um ritual quotidiano préestabelecido imposto por uma hierarquia profissional, distante do usuário, no qual as necessidades humanas e de trabalho são essencialmente manipuladas pela burocracia. $\mathrm{O}$ hospital psiquiátrico, enquanto instituição total, funciona no interior de uma rede de instituições totais que se defronta com pessoas que apresentam geralmente algum "distúrbio social". Exerce duas funções principais dentro do sistema social: a de punição e a de controle social do comportamento desviante do enfermo mental. A função terapêutica do hospital aparece praticamente superposta por estas duas dominantes. O paciente é ainda objeto de uma "carreira moral", influenciada pela categoria instituída de enfermo mental, expressão de um destino social de característica geralmente excludente.

Entretanto, a instituição total é também considerada instituição difusa (Basaglia \& Giannichedda, 1981), visto que difunde e transmite socialmente, através de suas práticas instituídas, concepções e representações de conteúdos excludentes que contribuem para construir e/ou reforçar estereótipos, estigmas e discriminações em relação ao usuário identificado como doente mental/desviante. Essa difusão virulenta, na sua dimensão sócio-afetiva, contagiaria e contaminaria todo o circuito institucional hospitalocêntrico, desde a atenção em saúde mental num ambulatório até o hospital, além de se estender para a sociedade como um todo.

Através de algumas pesquisas sobre representações sociais, pode-se perceber como funciona uma instituição difusa. Os resultados encontrados por Nóbrega (2003), sobre a dinâmica das representações sociais referentes ao "louco", elaboradas pelos membros de famílias de internos em hospitais psiquiátricos, evidenciam características exclusivamente negativas tanto no que concerne à instituição, quanto na atribuição de significação aos internos. Conforme evidenciam as representações dos familiares, os internos são considerados "violentos e perigosos", que na constelação representacional relativa à alteridade constituem-se em elementos figurativos e centrais em torno dos quais organiza-se um "cortejo de misérias" que modelam o perfil desses sujeitos, assim como o espaço social da reclusão que lhes é destinado. Diferentemente dessa qualificação, os membros das famílias dos internos representam a si mesmos como sofridos e nervosos. O sentido atribuído ao termo nervoso é freqüentemente apropriado pelos membros das famílias como uma forma de atitude defensiva na preservação de uma identidade diferenciada da caracterização do "louco", sobretudo, pela inevitável proximidade ameaçadora deste último, seja no que se refere às condições físicas de espaço habitacional, seja na reprodução de condutas, e até mesmo no consumo de medicamentos prescritos para o interno. 
Em atividades de tratamento hospitalar no Rio de Janeiro, Jurandir Costa (1989) observa que a expressão doença dos nervos é utilizada pelos pacientes para designar um conjunto sintomático de distúrbios nervosos que contradizem a nosografia tradicional da psiquiatria. Duarte (1986) analisa as diferenças semânticas da palavra nervoso, fazendo referência ao sistema nervoso, que aparece na linguagem popular como uma entidade difusa em todo o corpo, estabelecendo uma relação íntima com a cabeça e que não coincide com o sentido anatômico utilizado pela medicina. $\mathrm{O}$ autor destaca a oposição do termo quando associado aos verbos estar nervoso e ser nervoso, aspecto que aparece também na França com relação à terminologia estar doente e ser doente mental (Jodelet, 1989). O contato com o outro "doente" provoca, nesse caso, reações de aproximação ou de afastamento, podendo se constituir uma relação de confronto, com reações de defesa, de intolerância ao outro, inclusive atingir a violência com fins de defesa dos territórios entre o enfermo e o "normal", e com a utilização de mecanismos excludentes nas práticas sociais. $\mathrm{O}$ estudo de Jodelet também enfatiza as práticas emudecidas pelo silêncio do sofrimento psíquico, em que as famílias de uma comunidade rural na França, que acolhem sujeitos com acompanhamento médico para transtornos mentais, realizam formas de separação e distanciamento de objetos pertencentes e de uso pelo enfermo.

Nessa perspectiva, o processo de desconstrução da rede de instituições totais em saúde mental pressupõe uma estratégia política, institucional e técnico-profissional de desmontagem do circuito hospitalocêntrico e das representações sociais excludentes. Em contrapartida, tenta-se construir novas práticas e instituições que questionam continuadamente as formas recicladas de opressão, repressão e exclusão social do usuário. Essas mudanças permitiriam a manifestação de um fluxo dialógico nas práticas intra e interinstitucionais, como também invenções terapêuticas comprometidas com a sua liberdade e inclusão social. Todavia, são mudanças em construção sócio-histórica, contexto que lhes dá um ritmo culturalmente possível, muitas vezes lento. O novo sistema de redes institucionais deveria assim funcionar como um circuito integrado de serviços de saúde mental, com as funções terapêuticas e sócio-assistencial dominantes, tendo como porta de entrada as organizações sanitárias territoriais.

\section{O território, a cultura, o estilo de gestão e de atendimento na atenção psicossocial.}

Nas clínicas-escola de psicologia, o conceito de território é pouco utilizado, provavelmente por não se trabalhar junto com o planejamento distrital e não se atender uma clientela referente a uma área de atuação explícita, fato que dificulta a localização sócio-cultural dos usuários nos atendimentos. O território, na sua dimensão de área de abrangência dos atendimentos, num distrito de um município, refere-se "à área de responsabilidade de uma unidade de saúde. Baseia-se em critérios de acessibilidade geográfica e de fluxo da população. Deve ser constituída por conglomerados de setores censitários" (Sousa Unglert, 1999, p. 222). Entretanto, o terri- tório, enquanto microlocalismo, é gerador de uma dinâmica na qual os grupamentos humanos (por exemplo, famílias, creches, associação de moradores) se organizam numa territorialidade geográfica, política e simbólica. Nesta, pessoas e grupos estariam mais ligados ao espaço simbólico-cultural (ou comunitário) e às relações de afetividade, aí vivenciadas, do que ao espaço geográfico em si. A territorialidade mostra-se como uma âncora ou ponto de referência cultural em que se vive em conjunto com os outros por uma determinada duração de tempo.

A cultura perpassa também a organização sanitária, seu estilo de gestão e o trabalho terapêutico. Ela é principalmente linguagem e código, fornece

um referencial que permite aos atores dar um sentido ao mundo em que vivem e às suas próprias ações. Ela designa, classifica, liga, coloca em ordem. Define os próprios princípios de classificação que permitem ordenar a sociedade em grupos distintos, desde os grupos totêmicos até às categorias profissionais. Ela fornece esquemas de interpretação que dão sentido às dificuldades da existência, apresentando-as como elementos de uma ordem ou como fruto de sua perturbação. (Motta, 1997, p. 27)

Os estilos de gestão e de atendimento da organização CAPS estão, assim, influenciados por traços culturais da administração brasileira: "concentração de poder, personalismo, postura de espectador e o evitar conflito" (Prates \& Barros, 1997, p. 57). Aspectos que tendem a facilitar a prática de valores nem sempre democráticos e a reprodução de uma lógica corporativista. Entretanto, a consciência das contradições sociais e a possibilidade concreta de desconstrução institucional permitem uma leitura crítica que pode favorecer a emergência de brechas e caminhos alternativos para as novas práticas de atendimento, dando lugar a processos institucionais em autopoiesis (do grego poiesis: ação de fazer algo, criação), entendidos como possibilidade de criação e invenção institucional continuada, e dialeticamente opostos aos da instituição total. E cuja processualidade inventiva permitiria evitar cristalizações burocráticas nas ações profissionais, bem como mecanismos de reificação ideológica nas práticas quotidianas.

No território, a prática terapêutica modula-se de forma diferente do consultório: trabalha-se com a população local e no serviço comunitário. O centro de gravitação dos atendimentos em saúde mental se localiza no CAPS e o da saúde geral, no Programa de Saúde da Família (PSF). Esses serviços devem estar interconectados num circuito interinstitucional integrado no SUS. Situação que pode evitar a fragmentação dos atendimentos e ainda ser facilitadora do planejamento de área de saúde distrital, sobretudo concernente aos atendimentos domiciliares e às intervenções clínicas na rede pessoal significativa do usuário.

\section{Articulações entre as estruturas celulares dos atendimentos}

Aqui a idéia de rede remete a

uma articulação entre diversas unidades que, através de certas ligações, trocam elementos entre si, fortalecendo-se reciprocamente, e que podem se multiplicar em novas unidades, as 
quais, por sua vez, fortalecem todo o conjunto na medida em que são fortalecidas por ele, permitido-lhe expandir-se em novas unidades ou manter-se em equilíbrio sustentável. Cada nódulo representa uma unidade e cada fio um canal por onde estas unidades se articulam através de diversos fluxos. O princípio básico dessa rede é que ela funciona como um sistema aberto que se auto-reproduz, isto é, como sistema autopoiético. (Mance, 2001, p. 24)

Analogamente, a rede comunitária de serviços em saúde mental deveria funcionar como um sistema autopoiético no qual cada nódulo da rede representaria uma unidade sanitária, ou micro-organização (por exemplo, CAPS). Nessa, cada estrutura molecular de atendimento teria canais de comunicação, tanto dentro da própria unidade quanto fora dela, possibilitando a realização de ações integradas de caráter intra e interinstitucional, não somente com as instituições sanitárias, mas também com a justiça, igreja, escola, etc.

Destaca Maturana (1998), que um sistema autopoiético é constituído como unidade,

como uma rede de produção de componentes que em suas interações geram a mesma rede que os produz, e constituem seus limites como parte dele em seu espaço de existência... Em princípio, pode haver sistemas autopoiéticos em qualquer espaço em que se possa realizar a organização autopoiética. (p. 35)

Continua afirmando que

a conservação da organização de um sistema dinâmico em um meio de interações exige a correspondência estrutural entre o sistema e o meio. Quando esta correspondência estrutural se perde o sistema se desintegra, (p. 35)

pois o acoplamento estrutural falha na adaptação ao meio interferindo na autopoiesis.

Nesse sentido, o sistema de saúde mental em autopoiesis conserva sua organização e coerência interna na medida em que cada micro-organização e cada estrutura celular de atendimento funciona em sistema aberto, com interações contínuas e dialógicas. Nas conexões interinstitucionais, assim funcionando, ocorrem "adaptações adequadas" e complexas entre as estruturas celulares de atendimentos. Situação que permite evitar intervenções clínicas concorrentes, que provocam conflitos desagradáveis e falhas interativas. Essas "adaptações" se concretizam, na prática, através de mediações que possibilitam a

capacidade de se perguntar sobre as diversas estratégias disponíveis frente ao conflito, de refletir, formular questões significativas, aprender a aprender, transforma-se em meios ativos de enfrentar os conflitos e resistir às simplificações de velhos paradigmas. (Schnitman, 1999, p. 19)

A construção constante de diálogos, com reflexões críticas, co-participação e co-construção de significados, não se faz mediante um monitoramento hegemônico de profissionais sobre os outros, mas pelo trabalhar com os outros em prol da qualidade terapêutica, da colaboração solidária e comunitária. Nas estratégias quotidianas é fundamental a flexibilização do poder e do saber do profissional para que seja possível enfrentar a complexidade e o desenvolvimento da capacidade de se fazer alianças e invenções institucionais. No cotidiano, há momentos de recuo, de avanços, de "jogo de cintura", de rupturas momentâneas, de retomadas de discussões, assim por diante. Incidir na desconstrução de incrustações que dificultam essa dinâmica institucional parece ser o procedimento a ser adotado na prática para possibilitar a abertura de novos espaços e mediações.

\section{A estrutura celular do atendimento terapêutico}

$\mathrm{O}$ atendimento terapêutico, estrutura celular de uma microorganização, não pode ser reduzido a uma ilha de relações interpessoais e/ou contratransferenciais. Trata-se de um topo instituído, um espaço-lugar da relação terapêutica, inserido obviamente nas relações de poder, administráveis pela mediação dialógica e por meio de estratégias colaborativas e comunitárias que favoreçam "o respeito às diferenças, a coordenação na complexidade e contradição, a estruturação de acordos e a construção cultural de práticas democráticas nãorestritas exclusivamente a esperas" (Schinitman, 1999, p. 18).

$\mathrm{O}$ atendimento (do latim attendere: acolher) terapêutico (do grego terapéuo: tratar diligentemente) é entendido como ato de acolher, receber com cortesia, tomando em consideração e escutando atentamente a pessoa humana que procura o serviço para prestar cuidados relativos à demanda referente à sua problemática sócio-existencial e de saúde mental. Atender significa também: atentar, observar, notar, com uma metodologia apropriada ao campo do saber/fazer prático clínico. No quotidiano, a variabilidade dos atendimentos (psicoterapia, visita domiciliar, atividades de apoio social, etc.) depende então da demanda de cuidados à saúde mental do usuário, das condições concretas de intervenção da equipe multiprofissional e dos recursos terapêuticos disponíveis.

A unidade básica da rede de serviços é, como já foi visto, a própria estrutura celular do atendimento. Todavia, o que permite os atendimentos se realizarem em rede é a interligação profissional entre eles nas ações terapêuticas intra e interinstitucionais. A qualidade dos atendimentos em rede não se avaliaria pelo padrão de eficiência organicistareparatória, em cada estrutura celular, separadas umas das outras. Pois, nesse padrão, o ritual do ciclo reparatório (Goffman, 1980) funciona no sentido de "solucionar", de forma corretiva, o "mau funcionamento" orgânico do sujeito objetificado como doente mental.

Doravante, a preocupação não é mais na referida eficiência, mas na "eficácia da comunicação dialógico-terapêutica" (Vieira Filho, 2003). Essa permitiria, ao menos, avaliar no(s) encontro(s) dialógico-terapêutico(s) a construção de sentido e a re-significação da problemática sócio-existencial e de saúde mental, comunicada pelo próprio usuário, associando essa última a alguma modificação importante em seu modo de vida. Nessa avaliação, se incluiria também a capacidade de fluidez dos profissionais nas colaborações solidárias conjuntas, dentro e fora da micro-organização, no interior das respostas terapêuticas à demanda de cuidados à saúde mental do usuário. 


\section{Diversificar e integrar as ações} de cuidados à saúde mental

Sabe-se que uma estrutura celular não seria capaz de satisfazer toda a sua demanda genérica. Por isso a rede deve diversificar e integrar suas intervenções e recursos humanos e materiais de modo a poder atender, ao menos, a maioria dessas demandas, no conjunto das estruturas celulares. Situação que pode contribuir para o crescimento da rede e para a promoção das conversões das demandas advindas das instituições totais, gerando um novo circuito de demandas e intervenções mais condizente com o processo de subjetivação, liberdade e cidadania dos usuários.

O funcionamento adequado de cada estrutura celular supõe também uma gestão comunitária, na qual os trabalhadores vivenciam a cooperação nas relações de poder e interlocuções entre colegas. A horizontalização do poder facilita o fluxo comunicativo entre profissionais e a possibilidade de exercer diferentes papéis e funções relativas ao contexto interventivo multifacetado. Em se tratando de um trabalho em equipe, as diversas ações de saúde mental necessitam ser coordenadas entre elas numa coerência interna interdisciplinar entre saberes e fazeres.

Essas diversas ações estão incluídas num projeto terapêutico que lhes dá sentido e harmonia. A noção de projeto (do latim projetu, particípio passado de projicere, "lançar para diante") remete a um plano-ação, em desconstrução institucional, que engloba uma visão global da situação sócio-existencial e de saúde mental do(s) usuário(s) e meios operacionais susceptíveis de responder à(s) sua(s) demanda(s). Esse plano-ação orienta, em termos gerais, as decisões e se configura como um "lançar para diante" práticas em invenção, preocupadas com a inserção social e a qualidade de vida do(s) usuário(s). O projeto não se confunde obviamente com o programa terapêutico. No programa explicitam-se mais e pragmaticamente os pormenores de um tratamento ou acompanhamento terapêutico ligado ao projeto.

A prática de atendimentos terapêuticos supõe também uma lógica complexa (do latim complexus: o que tece em conjunto) e cotidiana, que se sucede e se atua habitualmente, no dia-a-dia. $\mathrm{O}$ hábito da prática de atendimento indica uma disposição duradoura aprendida pela repetição freqüente das ações de saúde mental, que podem ser automatizadas, pois não há necessidade de concentrar uma atenção especial para executar as tarefas. Contudo, quando não se re-inventa o quotidiano, as ações automatizadas podem dar origem à monotonia, ao conservadorismo, à autonomização das condutas profissionais, que podem contribuir para a reprodução ideológica e acrítica das intervenções. Em processo de invenção,

o cotidiano também é ou pode vir a ser o lócus da atenção, da observação atenta de nós mesmos, do grupo ou grupos aos quais nos ligamos, das ações que executamos, conteúdo e diversidade de nossos pensamentos do dia-a-dia... E, é esta observação atenta que contém a potencialidade de ser a inovação ou a transformação no cotidiano. (Mesquita, 1995, p. 16)
Na constelação dos serviços psicossociais, a atenção/ invenção cotidiana permitiria uma construção da prática mais coerente com a desconstrução institucional. Entretanto, uma das dificuldades atuais é a presença, não rara, de núcleos institucionais que se configuram como reprodutores de intervenções de tendência organicista-reparatória. Ao invés de permitirem a emergência de espaços criativos de questionamento e reinvenção das práticas terapêuticas, apresentam efeito inverso. Quer dizer, a morte da atenção/invenção tende a engendrar uma prática reificante, rigidificando os significantes discursivos, facilitando, assim, a autonomização dos atendimentos.

Um exemplo não é o diagnóstico psiquiátrico em si, mas seu etiquetamento (Basaglia, 1981, pp. 384-5), visto que tende a produzir intervenções imobilizantes e a coisificação do sujeito que sofre. Esse etiquetamento implica uma leitura objetificante da problemática de saúde mental do usuário, durante a rotina técnica psiquiátrica tradicional, que atribui à doença mental uma representação unidimensional organicista, dogmática e naturalizada. Os atendimentos psiquiátricos corridos, de cinco a dez minutos nos ambulatórios, as apressadas consultas hospitalares e nas emergências psiquiátricas tendem, muitas vezes, a reproduzir este etiquetamento, dificultando o processo de reforma no SUS. Em contraste, notam-se, nos serviços psicossociais, situações conflituosas com os serviços hospitalares psiquiátricos. Alternativas devem ser procuradas no plano político e técnico-profissional para se poder tentar superá-las.

\section{Psicoterapia e rede social}

A Portaria 336/2002 do Ministério da Saúde institui a psicoterapia no CAPS. Entende-se por psicoterapia, na atenção psicossocial (Vieira Filho, 1998a), uma modalidade de atendimento clínico psicológico ao sujeito-social que tem como eixo central a dialogicidade na relação terapêutica e a realização temporal a curto ou longo prazo. Seu objetivo maior é o bem-estar e melhor inserção social do usuário. Nesse processo relacional, afetivo e cognoscitivo, ele expõe livremente sua experiência de vida, sem medo ou expectativa de julgamento moralista e normalizador.

O psicoterapeuta acompanha constantemente, na prática cotidiana, a demanda de cuidados à saúde mental do usuário, entendida como solicitação de atenção e de busca de sentido de sua experiência existencial e de saúde mental. Situação inserida nas regras instituídas do contrato terapêutico, cujas ações concretas pressupõem a organização singularizada do enquadre, com estratégias e recursos utilizados que respeitem a cultura vivenciada do usuário. Esse enquadre pode variar em harmonia com a referida demanda e com a necessidade de cuidados complementares que requeiram uma conexão intra e/ou interinstitucional como, por exemplo: apoio para inserção social, visita domiciliar, ações jurídicas, apoio espiritual e/ou religioso, etc. (Vieira Filho, 2001).

Dentro dos limites previstos no serviço, a duração do atendimento deve ser negociada com o usuário, sem que haja uma imposição rígida, às vezes, induzida pela "produtividade" a nível burocrático, se superpondo a sua demanda de 
cuidados à saúde mental. $\mathrm{O}$ espaço psicoterápico, de caráter essencialmente simbólico, intersubjetivo e comunicativo, não pode se confundir com o espaço físico da sala de atendimento do estabelecimento, pois há usuário que precisa ser atendido em domicílio. Pode-se fazer psicoterapia em espaços terapêuticos nos quais se evite interações invasivas, se mantenha o sigilo profissional e as regras cidadãs do contrato.

$\mathrm{O}$ face-à-face pode ser importante, mas se o usuário se sentir inibido e/ou apresentando resistências, o terapeuta pode tentar uma situação negociada na qual ele possa falar sem ter um olhar dirigido ao psicoterapeuta. As necessidades básicas, as aspirações sociais e pessoais, o processo identitário, os aspectos somáticos (por exemplo, alimentação, sono, ritmos biológicos), psicossomáticos e os eco-ambientais (por exemplo, saneamento básico, poluição, habitação) merecem uma atenção importante no decorrer dos atendimentos e podem, às vezes, indicar a necessidade de intervenção clínica e de se trabalhar em colaboração com outros profissionais.

Nos encontros terapêuticos, as conversações dialógicoterapêuticas (Vieira Filho, 2003) não são meras ações interativas interpessoais, mas momentos nos quais os interlocutores compartilham empaticamente convicções, significados, emoções, conhecimentos, numa linguagem comum de compreensão mútua, com criticidade e afeto. A dialogicidade (Vieira Filho \& Morais, 2003) requer uma relação de poder em cooperação, e não em dominação, que se repercute no desenvolvimento da comunicabilidade na estrutura celular do atendimento e na intercomunicabilidade na rede de serviços. Postura que se contrapõe ao uso de procedimentos invasivos, particularmente aqueles relativos ao universo sócio-cultural do usuário. É o caso, por exemplo, de tarefa terapêutica não relacionada com sua cultura vivenciada, podendo induzí-lo a aceitar com aderência as representações e visão de mundo do terapeuta. Ao contrário, respeitam-se as diferenças de visões de mundo e se problematiza, junto com o usuário, sua situação sócio-existencial e de saúde mental.

Os processos conscientes e inconscientes e a ressignificação do sofrimento, passam aqui por um olhar clínico que privilegia a dinâmica das relações humanas de um sujeito situado numa sociedade, cultura e história. Por isso o entendimento da rede pessoal significativa do usuário (Sluzki, 1997; Vieira Filho, 1998b) é fundamental, particularmente quando se quer perceber as teias de conflito(s), o potencial familiar de apoio ou não em situação de crise, o núcleo relacional a ser ativado para uma melhor inserção social do usuário, etc. Porém não se pode confundir sua rede significativa com a rede de apoio que o terapeuta pode construir junto com ele. No primeiro caso, mapeiam-se as pessoas e grupos com os quais ele tem uma relação significativa (por exemplo, confiança, profissional, mais afetiva); no segundo, distingue-se neste mapeamento aquelas pessoas e/ou grupos que podem ser ativados diretamente (intervenção na rede), ou indiretamente (por iniciativa do usuário ou outros implicados no atendimento), no sentido de contribuir para seu bem-estar. Em todo caso, a rede de serviços também pode se constituir como rede de apoio na medida em que existam profissionais disponíveis e solidários para ajudar o usuário em cuidados específicos.

\section{Conclusão}

Entende-se que o sistema de saúde funcionaria como um circuito integrado de unidades sanitárias, tendo como portas de entrada, no território, o Programa de Saúde da Família (PSF) para a saúde geral e o serviço psicossocial (CAPS) para a saúde mental. A dinâmica deste circuito seria de característica autopoiética, pois possibilitaria a reprodução institucional do processo desconstrução/invenção da prática de cuidados à saúde mental, qualificando continuadamente os atendimentos em beneficio dos usuários. Trocas sociais entre interlocutores e mudanças nas representações de conteúdos excludentes seriam possíveis e freqüentes. Situação essa, que facilitaria o equilíbrio sustentável nas interações contínuas entre as organizações sanitárias e as estruturas celulares de atendimento terapêutico. Haveria abertura de canais de comunicação intra e inter organizações (formais e informais), com intervenções articuladas umas com as outras e a concretização de mediações dialógicas, bem como a participação democrática dos atores sociais, sobretudo no contexto de uma gestão territorializada. Concomitantemente, as ações de saúde mental tenderiam a se diversificar numa coerência complexa, mas articulada em um projeto terapêutico que possibilitasse, quando necessário, a ativação da rede pessoal significativa, na tentativa de construir uma rede de apoio ao usuário, intencionando uma melhor inserção social para o mesmo.

Conseqüentemente, o usuário não seria mais considerado como sujeito solitário, como ocorre geralmente nas psicoterapias tradicionais (Nathan \& Stengers, 1999), mas como sujeito-social, entendido numa concepção relacional na qual não se focaliza a pessoa atomizada, mas inserida culturalmente, participante de uma sociedade, de suas redes sociais e ambiente ecológico. Assim, o processo psicoterápico psicossocial pressupõe também uma prática complexa, articuladora de saberes e fazeres, numa dialógica quotidiana ancorada no sócio-histórico.

Entretanto, parece haver uma decalagem entre a teorização exposta e a prática cotidiana dos serviços psicossociais, visto que os profissionais se deparam, muitas vezes, com dificuldades nas interações interinstitucionais, na concretização da territorialização, nas teias de conflitos interpessoais, no clientelismo político, nas políticas de abandono da clientela dita "pobre", no pouco planejamento local e distrital, etc. Tudo indica que os passos das mudanças institucionais ocorrem lentamente. Todavia, é importante se poder encontrar alternativas políticas e técnico-profissionais, principalmente em nível de área de saúde e distrito sanitário, para que seja possível a superação dessas dificuldades, às vezes, estruturais.

\section{Referências}

Barros, D. D. (1994). Cidadania versus periculosidade social: a desinstitucionalização como desconstrução de um saber. In P. Amarante (Org.), Psiquiatria social e Reforma Psiquiátrica (pp. 171-194). Rio de Janeiro: FIOCRUZ. 
Barus-Michel, J., Giust-Desprairies, F., \& Ridel, L. (1996). La psychologie sociale clinique. In J. Barus-Michel, F. Giust-Desprairies, \& L. Ridel (Orgs.), Crise. Approche psychosociale clinique (pp. 261-268). Paris: Desclée de Brouwer.

Basaglia, F. (1981). Presentazione a che cos’è la psichiatria? In F. O. Basaglia (Org.), Basaglia Scritti I 1953-1968 (pp. 384-393). Torino: Einaudi.

Basaglia, F., \& Gianichedda, M. G. (1981). Il circuito del controllo: dal manicomio al decentramento psichiatrico. In F. O. Basaglia. (Org.), Basaglia Scritti II 1968-1980 (pp. 391-408). Torino: Einaudi.

Costa, J. F. (1989). Psicanálise e contexto cultural. Rio de Janeiro: Campus.

Duarte, L. F. (1986). Da vida nervosa nas classes trabalhadoras urbanas $\left(2^{\underline{a}}\right.$ ed). Rio de Janeiro: Zahar/Cnpq.

Goffman, E. (1980). Asylums. Le istituzioni totali ( $7^{\mathrm{a}}$ ed). Torino: Einaudi.

Jodelet, D. (1989). Folies et representations sociales. Paris: Presses Universitaires de France.

Mance, E. A. (2001). A revolução das redes. A colaboração solidária como alternativa pós-capitalista. Petrópolis: Vozes.

Maturana, R. H. (1998). Da biologia à psicologia. Porto Alegre: Artes Médicas.

Mesquita, Z. (1995). Do território à consciência territorial. In Z. Mesquita \& C. R. Brandão (Orgs.), Território do cotidiano. Uma introdução a novos olhares e experiência (pp. 76-92). Porto Alegre: EDUNISC.

Motta, F. C. P. (1997). Cultura e organizações no Brasil. In F. C. P. Motta, \& M. P. Caldas (Orgs.), Cultura organizacional e cultura brasileira (pp. 25-37). São Paulo: Atlas.

Nathan, T., \& Stengers, I. (1999). Médicins et sorciers. Paris: SANOFISYNTHÉLABO.

Nóbrega, S. M. da (2003). Représentations sociales de la folie par les familles de malades mentaux au nord-est du Brésil: le cas João Pessoa. Paris: Presses Universitaires do Septentrion.

Prates, M. A. S., \& Barros, B. T. (1997). O estilo brasileiro de administrar: sumário de um modelo de ação cultural brasileiro com base na gestão empresarial. In F. C. P. Motta \& M. P. Caldas (Orgs.), Cultura organizacional e cultura brasileira (pp. 55-69). São Paulo: Atlas.

Rotelli, F., De Leonnardis, O., \& Mauri, D. (1992). Deistituzionalizzazione, un’altra via. In A. Debernardi, R. Mezzina, \& B. Norcio (Orgs.), Salute mentale: pragmática e complessità (pp. 55-69). Trieste: Posto delle Fragole.

Schnitman, D. F. (1999). A mediação: novos desenvolvimentos geradores. In D. F. Schnitman \& S. Littlejohn (Orgs.), Novos paradigmas em mediação (pp. 101-124). Porto Alegre: ARTMED.

Sluzki, C. E. (1997). A rede social na prática sistêmica. Alternativas terapêuticas. São Paulo: Casa do Psicólogo.

Sousa Unglert, C. V. de (1999). Territorialização em sistemas de saúde. In E. V. Mendes (Org.), Distrito Sanitário. O processo social de mudança das práticas sanitárias do Sistema Único de Saúde (pp. 221-235). São Paulo: Hucitec/Abrasco.

Vieira Filho, N. G. (1997). L'analyste et le quotidien. Le circuit institutionnel. Pratiques de Formation/Analyses, 4(34), 91-104.

Vieira Filho, N. G. (1998a). Fundamentos do atendimento psicoterápico psicossocial. In N. G. Vieira Filho (Org.), Clínica psicossocial. Terapias, intervenções, questões teóricas (pp. 37-53). Recife: Editora UFPE.

Vieira Filho, N. G. (1998b). Situação de "crise" e atendimento psicossocial à família. In N. G. Vieira Filho (Org.), Clínica psicossocial. Terapias, intervenções, questões teóricas (pp.55-73). Recife: Editora UFPE.

Vieira Filho, N. G. (2001). Souffrance psychotique et esprit obsédant. Entre l'action thérapeutique et l'accueil religieux. Bulletin de Psychologie, 54(2), 137-145.

Vieira Filho, N. G. (2003). O processo dialógico na atenção terapêutica psicossocial. Contribuições de Paulo Freire. In Anais do III Colóquio Internacional Paulo Freire. João Pessoa: Editora UFPB.

Vieira Filho, N. G., \& Morais, S. R. S. (2003). A prática da clínica psicossocial. Construindo o diálogo com o cliente dito "psicótico". Psicologia: Ciência e Profissão, 23(3), 34-41.

1 Na reforma psiquiátrica distinguem-se, ao menos, duas principais orientações políticas em contraste (Barros, 1994; Rotelli, De Leonnardis, \& Mauri, 1992). De um lado, a desospitalização, com características neo-liberais e mais voltada à diminuição das despesas públicas. De outro, a desinstitucionalização, como desconstrução da rede de instituições totais em saúde mental que se refere mais às políticas públicas solidárias, em equilíbrio sustentável, e de não abandono ao usuário.

Nilson Gomes Vieira Filho, doutor, é professor adjunto no Departamento de Psicologia e no Laboratório de Pesquisa em Psicologia Clínica, Universidade Federal de Pernambuco. Endereço para correspondência: Av. Boa Viagem, 4364, Apt. 703. Boa Viagem. Recife, PE. CEP: 51021-000. Fone: (81) 3326-0535. E-mail: ngovi@uol.com.br

Sheva Maia da Nóbrega, doutora, é professora adjunta no Departamento de Psicologia, Universidade Federal de Pernambuco. E-mail: sheva@ufpe.br 